\title{
DO CHÃO DA FÁBRICA À FÁBRICA CARCERÁRIA
}

\section{FLOOR FACTORY TO PRISON FACTORY}

\author{
Maysa Carvalhal Dos Reis Novais ${ }^{1}$
}

\section{RESUMO}

O breve artigo discute, através das lentes do materialismo histórico, a política criminal e sua capacidade programada de alienar os sujeitos e ser instrumento de controle de classe. Por meio da dialética, tece comparações entre a dominação capitalista sobre o proletariado e o subjugo do indivíduo criminalizado, excluído do processo de produção e refém do Direito burguês.

Palavras-chave: Alienação; Cárcere; Política Criminal

\begin{abstract}
This brief article discusses, through historic materialism lens, criminal policy and ability scheduled to alienate subjects and behave like class control tool. By means of dialetic, weaves comparissons between the capitalist domination of proletariat and subjugation of criminalized individuo, excluded from the production process and hostage of bourgeois law.
\end{abstract}

Keywords: Alienation; Prison; Criminal policy

\footnotetext{
${ }^{1}$ Mestranda bolsista da CAPES em Teorias Jurídicas Contemporâneas pela Universidade Federal do Rio de Janeiro (UFRJ), da linha de pesquisa "Sociedade, Direitos Humanos e Arte". Rio Grande do Norte (Brasil). E-mail: maysacarvalhal@gmail.com.
} 


\section{CONSIDERAÇÕES INICIAIS}

A criminologia Crítica se firma pelo debate estrutural da produção do crime, da criminalidade e do criminoso, discutindo poder, instituições jurídicas, criminalização seletiva ao relacionar entre si as relações econômicas, políticas e jurídicas.

Nesse sentido, recebeu e recebe muitas influências da literatura marxista para, através de uma teoria do conflitos de classes, explicar as contradições que permeiam essas três esferas e discutir a questão criminal dentro do processo dialógico do capitalismo.

A estrutura econômica, segundo Cirino Dos Santos (2015), percebe a produção e circulação de mercadorias, com o objetivo de lucro e através da apropriação de mais-valia como trabalho não remunerado; a estrutura do Direito, institui a "legalidade" da desigualdade social entre a classe capitalista (proprietária dos meios de produção e circulação) e a classe trabalhadora(possuidora de força de trabalho vendida ao capitalista pelo preço do salário); e a estrutura política do Estado garante as desigualdades sociais nas relações econômicas e nas formas jurídicas respectivas através do poder coercitivo do Sistema de Justiça Criminal.

Quando Melossi e Pavarini(1975) definem a relação cárcere/fábrica como a matriz histórica da sociedade capitalista, definindo o cárcere como a principal instituição de controle social e a fábrica como a principal instituição da estrutura de circulação de mercadorias, estão também se valendo das lentes marxistas para denunciar a objetivação do homem pelo sistema penal inquisitorial.

Com o método de levantamento de referencial teórico, discute-se o modo de produção capitalista como ponto de interseção dos conflitos sociais, caminhando por algumas obras de Marx e por criminólogos marxistas para discorrer como alguns conceitos como mercadoria, alienação, mais-valia e outros se aplicam na compreensão estrutural da criminalização penal na sociedade capitalista.

\section{A FÁBRICA DO CÁRCERE: A MÁQUINA CAPITALISTA DE INCRIMINAR E ENCARCERAR}

O sistema punitivo compreende uma lógica de poder movimentada pela estrutura do Estado, de modo que desde tempos remotos a organização do sistema punitivo é manifestação do 
controle social. A punição hegemônica na sociedade moderna está associada à formação do eu da sociedade burguesa/ capitalista (MENEGAT, 2006). Segundo Menegat:

se a Reforma Protestante ajudou a moldar o eu em sua liberdade e autonomia, que caracteriza o espírito burguês, o sistema punitivo teria sido o seu outro tanto, necessário à disciplina e moldura do eu dos trabalhadores imprescindíveis para a indústria nascente. $\mathrm{O}$ que Calvino e Lutero foram para as necessidades morais do bom burguês, que facilitaram o desenvolvimento da lógica mercantil da sociedade capitalista, as casas de correção e sua terapêutica disciplinar embrutecedora o foram para as massas que, literalmente, amassadas e derrotadas, foram transformadas em corpos dóceis para o trabalho fabril.

Ao analisar a dissolução do mundo feudal e o processo histórico de separação entre produtor e meio de produção, a chamada acumulação primitiva do capital nos séc. XV e XVI, Melossi a Pavarini (2006) apontam como conseqüência a expropriação dos meios de produção e expulsão dos trabalhadores do campo para a sua concentração nas cidades onde deveriam ser transformados em operários.

Os trabalhadores que deveriam dispor sua força de trabalho nas manufaturas eram absolutamente inaptos à disciplina do trabalho assalariado. Em fins do século XVI, a escassez de força de trabalho era crescente e gerava reclamações sobre o ócio dos mendigos, pois, quando as condições de trabalho eram precárias, estes preferiam sobreviver da caridade privada ao trabalho regular, optando por mendigar a trabalhar por baixos salários e em situações muito precárias. Assim, as casas de correção foram uma forma de impelir os trabalhadores à aceitação de empregos miseráveis. Assim, Melossi (2004, p. 130) afirma que:

\footnotetext{
Vindos das ruínas do feudalismo, capital e operários 'livres' são colocados frente a frente. E são reunidos materialmente na manufatura. Para esse proletariado em formação, tal abraço não é voluntário nem de modo algum prazeroso. Ele deve adaptar-se à clausura, à falta de luz e de espaço, à perda daquela relativa autonomia permitida pelo trabalho nos campos, para submeter-se à autoridade incondicional do capitalismo, na mais brutal e fatigante monotonia e repetitividade. Não é por acaso, como veremos, que manufatura e cárcere tenham historicamente uma mesma e interdependente origem. (grifo meu)
}

O cárcere desde essa época é lugar de "formação" (não tomando aqui o termo no sentido de construção, já que o cárcere, em verdade, destrói. Tomemos o sentido de produção, neste caso, lugar de produção) de homens servis, transformando o criminoso rebelde em sujeito disciplinado e adestrado ao trabalho fabril. Funcionava como instrumento de adestramento dos antigos camponeses que repeliam os novos métodos de produção, para o trabalho nas manufaturas pela assimilação da disciplina fabril. As casas de correção cumpriram o objetivo de formar sujeitos dóceis e úteis, pela submissão ao trabalho obrigatório e uma rígida disciplina que deveriam desviar 
os trabalhadores expropriados, potenciais mendigos, vagabundos e bandidos, do caminho do ócio e da vagabundagem, educando e domesticando para o trabalho assalariado. As casas de correção destruíram a resistência do trabalhador em adentrar o mundo da manufatura, reduzindo a estranheza a esse espaço. Melossi afirma que a fábrica é o mistério revelado da moderna prisão e o operário o destino ao qual o delinqüente está condenado. Isto é, tanto o operário quanto delinquente estão condenados a suas prisões, seja no mundo do trabalho, seja no mundo da justiça penal.

A prisão desenvolve esse papel de ser instrumento para compelir o homem livre a aceitar as condições degradantes de trabalho ante a possibilidade de ir para as casas de correção fazer trabalhos pesados dificilmente aceitos por homens livres.

A assimilação da disciplina capitalista própria ao seu processo de produção, dizem Melossi e Pavarini(2006), desempenhava um papel fundamental, devendo o preso ter um comportamento regrado e submisso à autoridade. O cárcere era um espaço de produção onde o trabalhador deveria aprender a disciplina da produção e o apego à disciplina estava em aspectos como o respeito à ordem, limpeza, vestuário, comida, ambiente saudável, linguagem proibida. As casas de correção eram a célula embrionária do controle físico e ideológico do proletariado nascente para sua produção e reprodução, formando uma força de trabalho que, pelas atitudes morais, saúde física, capacidade intelectual, conformidade às regras, hábito da disciplina e obediência, estaria adaptada ao regime da fábrica.

Os espaços correcionais eram os atos preparatórios para a reclusão no ambiente da fábrica, incluía o trabalhador no processo de educação para o obediente civil e bom proletário, subserviente e produtivo. O preso ia assumindo um padrão de conduta útil ao processo de trabalho capitalista, de modo que os corpos e mentes dos homens modernos foram sendo moldados às necessidades capitalistas pela associação da prisão, da família mononuclear, escola, hospital e manicômio (MELOSSI e PAVARINI, op. cit. p. 46).

Para Melossi e Pavarini(2006), a tentativa de transformar o trabalho carcerário num trabalho produtivo foi frustrada, pois, do ponto de vista econômico, o cárcere não alcançou grandes resultados, mas a prisão teve sucesso na transformação dos criminosos em proletários, pois o “objetivo desta produção não foram tanto as mercadorias quanto os homens” (Idem, p. 211).

Os autores referidos falam de um processo dialético de destruição e reconstrução, em que a condição de proletário é imposta ao condenado como única possibilidade de sobrevivência do não-proprietário. O não-proprietário preso deve ser transformado em proletário, a partir da aceitação da condição subordinada e do reconhecimento da disciplina do salário. A educação para o trabalho assalariado é o único instrumento para satisfação das necessidades pessoais, com a conseqüente 
aceitação do status de não-ser proprietário. Arrematam brilhantemente: “O cárcere assume, portanto, a dimensão de projeto organizativo do universo social subalterno, modelo a ser imposto, espalhado, universalizado" (Idem, p. 216.)

Nesse mesmo caminho, Foucault afirma que o cárcere deveria fabricar proletários, requalificando o interno em operário dócil, impondo a forma "moral" do salário como condição de sua existência e adquirindo amor e hábito ao trabalho. Conclui Foucault que a utilidade do trabalho penal não era o lucro e "nem mesmo a formação de um trabalho útil, mas a constituição de uma relação de poder, de uma forma econômica vazia, de um esquema de submissão individual e de seu ajustamento a um aparelho de produção". (FOUCAULT, 1987, p. 217)

É assim que se concluir a função ideológica do encarceramento que é formar o sujeito servil e alienado, estranho à sua realidade anterior ao aprisionamento, por se compreender com os valores ensinados como úteis para a sociedade fora do cárcere, ser bom trabalhador, produtor de riqueza e não contestador dos ditames do Estado, pois que compreende a hierarquia a que está subordinado, entende agora seu lugar no mundo do capital, aceita esta posição e sente-se pleno ao receber a parte que lhe cabe como não-proprietário do "latifúndio.

Acerca da observação do sistema punitivo e de sua função na ordem jurídica capitalista de garantidor da propriedade privada, Pasukanis(1989, p. 161) aponta a inserção do Direito Penal e do Processo penal na lógica capitalista em que os delitos e as penas assumem posição de prestação e contraprestação ao a norma penal negociar a quantidade de liberdade a ser retirada em detrimento do ato criminoso.

Melossi e Pavarini (op. cit. p. 264-266) apresentam os enlaces entre o universo da fábrica e o universo do cárcere:

1. Se o contrato de trabalho pressupõe formalmente "empregador" e "prestador", enquanto "sujeitos livres" num plano de paridade, a relação de trabalho determina, ao contrário, a necessária subordinação do proletário ao empresário. Não é diferente na relação punitiva: a "pena como retribuição" pressupõe "o homem livre"; o "cárcere" tem "o homem escravo" à sua disposição.

2. A discricionaridade máxima daquele que oferece trabalho na utilização da força de trabalho do prestador coincide, historicamente, com a mesma "deducibilidade do corpo" deste último no objeto da relação; isso não é diferente do que ocorre na relação disciplinar própria da pena como execução.

3. Como o contrato de trabalho entre iguais ("relações horizontais") cria um "superior" e um "inferior", assim a pena-retribuição cria (é) execução penitenciária, ou seja, um aparato de "relações verticais".

4. A "subordinação do trabalho" é exercício de um poder conferido pelo "contrato". A "subordinação do cárcere" é exercício do poder conferido pela "pena-retribuição".

5. Na relação de trabalho, a subordinação do prestador de trabalho é (também) "alienação pelos/dos meios de produção". Na relação penitenciária, a subordinação do preso é "expropriação" (também) pelo/do próprio corpo". 
6. A liberdade contratual do proletário encontra seu próprio objeto na "prestação como conteúdo inativo" (perda da liberdade por um quantum de tempo). A essa perda de liberdade e de autonomia faz frente o poder disciplinar do empresário. O mesmo acontece na pena carcerária: o objeto da pena é a "privação de um tempo" (quantum de liberdade) que deverá, no processo de execução, ser vivido como sujeição.

7. O trabalho subordinado (labor, travail etc) como prestação é esforço penoso, é sofrimento, é "pena" para o proletário. A pena carcerária, como conteúdo da retribuição que se molda sobre o exemplo da manufatura-fábrica, é essencialmente "trabalho".

8. Se o trabalho subordinado é portanto coação, a pena carcerária é o "nível mais alto" (ponto terminal e ideal) da coação. Daí deriva a função ideológica principal da penitenciária: a hipótese emergente do cárcere como universo onde a situação material do submetido (internado) é sempre "inferior" à do último dos proletários.

9. A penúria do trabalho subordinado é "diretamente proporcional" ao grau de subordinação, i.e., ao nível da perda de autonomia e independência do prestador. A pena, como aparato disciplinar que se molda sobre o exemplo da manufatura-fábrica, enquanto perda total da autonomia, representa o "ponto mais elevado" de subordinação e, por conseguinte, de sofrimento.

10. O momento disciplinar na relação de trabalho coincide com o momento institucional. Em outras palavras, o "ingresso" do prestador de trabalho (contratante) na fábrica, no lugar onde aquele que oferece trabalho (outro contratante) coativamente organiza os fatores de produção. $\mathrm{O}$ mesmo se dá na relação punitiva: o condenado (sujeito livre) torna-se sujeito subordinado (preso) quando "ingressa" na instituição penitenciária.

11. E finalmente: a "fábrica é para o operário como um cárcere" (perda da liberdade e subordinação): o "cárcere é para o interno como uma fábrica" (trabalho e disciplina) (grifo meu)

Da fala comparativa da estrutura hierárquica das relações na fábrica e na prisão, depreende-se que a subordinação e alienação são forças principiológicas que regem tanto o proletário quanto o encarcerado. Em um, a alienação é dos meios de produção, em outro, a alienação é do corpo refém e da consciência da falta de liberdade.

Se o castigo é a subtração da liberdade, ao tomar o tempo do condenado, expropriase o resultado da produção não realizada e, por conseguinte, rouba-se não só a fração de riqueza que lhe seria concedida no mundo do trabalho fora da prisão, mas o corpo, a energia produtiva e a mente (a ideia que se tem de si e do mundo). A privação de tempo é vivida como a maior sujeição de todas possível; nas palavras de Melossi e Pavarini, o submetido está em situação inferior à do último dos proletários, pois a pena carcerária é o nível mais alto de coação.

Na síntese emblemática dos autores, "a fábrica é para o operário como um cárcere”, pois que também se perde a liberdade e subordina-se; e "o cárcere é para o interno como uma fábrica”, já que se instituem como bases o trabalho e a disciplina. Arremata:

(...)a natureza propedêutica, subalterna, da instituição faz com que, para este fim, baste a experiência do tempo escandido, do tempo medido, a forma ideológica vazia, que nunca é apenas ideia, mas que morde na carne e na cabeça do indivíduo que se deve reformar, estruturando-o com parâmetros utilizáveis pelo processo de exploração.” (op. cit. p. 91) 
Assim como o crime é o produto de um contexto político e social de atribuição de sentido ao que se considera deplorável (ou quem se considera indesejado)(CHRISTIE, 2013), a pena de prisão é, também, apenas uma categoria dentre muitas outras possíveis de enfretamento do conflito. Assim, na sociedade capitalista, o direito penal capitalista, com seus valores de submissão do homem pelo homem, instaura um tipo de subjetividade em que a representação do homem abstrato e do trabalho humano abstrato são avaliados em tempo. São os dizeres:

A privação de liberdade, ditada pela sentença do tribunal, por um certo período de tempo é a forma específica pela qual o direito penal moderno, burguês-capitalista, realiza o princípio da reparação equivalente. Esta forma está inconscientemente, embora profundamente, ligada à representação do homem abstrato e do trabalho humano abstrato avaliados em tempo. Não foi por acaso que esta modalidade de apenamento foi implantada e tida como natural precisamente no século XIX, ou seja, em uma época na qual a burguesia pôde desenvolver e aprimorar todas as suas características. (PASUKANIS, 1989, p. 158)

\section{2. "PRISÃO É UM LUGAR DE GESTÃO DE CLASSE" ${ }^{2}$}

Quando Marx denunciou que a sociedade capitalista é marcada pelo constante antagonismo de classe, ele alarda em um só brado as contradições da exploração estrutural da sociedade burguesa, situa sua fala na compreensão da existência da cisão entre os proprietários e os não-proprietários.

É preciso invocar o marxismo sempre para identificar o caráter ideológico das formas jurídicas e políticas do Estado, para clarear a relação entre o jurídico e o econômico e entre o jurídico e o político (o Direito como fala legal da politica), relacionando o modo de produção capitalista com as contradições das estruturas de poder.

A inserção da questão criminal na estrutura do modo de produção capitalista é decorrente da lente da historicidade para enxergar as manifestações sociais e, neste caso, corresponde à noção de que Direito e Estado não podem ser explicados sem o contexto da economia política.

Sobre a essência da concepção materialista da história, do ser social e consciência social, o reflexão sobre ideologia é útil:

(...) não partimos do que os homens dizem, imaginam e representam, tampouco do que eles são nas palavras, no pensamento, na imaginação e na representação dos outros, para depois

\footnotetext{
${ }^{2}$ Remeto o leitor ao livro do qual retiro esta frase, "Pelas mãos da Criminologia: O controle penal para além da (des)ilusão", de Vera Regina P. de Andrade)
} 
se chegar aos homens de carne e osso; mas partimos dos homens em sua atividade real, é a partir de seu processo de vida real que representamos também o desenvolvimento dos reflexos e das repercussões ideológicas desse processo vital. (MARX; ENGELS, 1998, p. 19)

É por isso que Marx e Engels (1998, p. 19) expõem:

A consciência nunca pode ser mais que o ser consciente; e o ser dos homens é o seu processo de vida real. E, se, em toda a ideologia, os homens e suas relações nos aparecem de cabeça para baixo como em uma câmera escura, esse fenômeno decorre de seu processo de vida histórico, exatamente como a inversão dos objetos na retina decorre de seu processo de vida diretamente físico.

Com isso se diz que o modo de produção da vida material condiciona o processo de vida social, política e intelectual. Não é a consciência dos homens que determina o seu ser; ao contrário, é o seu ser social que determina a sua consciência. (MARX, 1985, p. 233).

\title{
2.1. A alienação (estranhamento) dos outsiders
}

A alienação (ou o estranhamento) do homem é um dos sintomas da sociedade capitalista, que aperfeiçoa os mecanismos de exploração de uma classe pela outra em seus níveis materiais e subjetivos. É uma forma de manter sob controle o proletariado em detrimento dos interesses burgueses.

Nos "Manuscritos Econômico- filosóficos", ao falar do trabalho estranhado e da propriedade privada, Marx desenvolve:

\begin{abstract}
A partir da própria economia nacional, constatamos que o trabalhador baixa à condição de mercadoria e à da mais miserável mercadoria, que a miséria do trabalhador põe-se em relação inversa à potência e à grandeza da sua produção(...)

$\mathrm{O}$ trabalhador se torna tanto mais pobre quanto mais riqueza produz, quanto mais a sua produção aumenta em poder e extensão. (...)Com a valorização do mundo das coisas aumenta em proporção direta a desvalorização do mundo dos homens. (...)

Este fato nada mais exprime, senão: o objeto que o trabalho produz, o seu produto, se lhe defronta como um ser estranho, como um poder independente do produtor. O produto do trabalho é o trabalho que se fixou num objeto, fez-se coisal, é a objetivação do trabalho. (2015. p 79-80)
\end{abstract}

No fato determinado de que o trabalhador se relaciona com o resultado de sua produção como com um objeto estranho, tem-se as consequências de: à impotência gradual do trabalhador caminha o seu desligamento de si, quanto mais energia coloca na produção, menos retém 
em si, de modo que "a vida que ele concedeu ao objeto se lhe defronta hostil e estranha."(Op. Cit. p. 81)

Por ser assim, o estranhamento se dá com a construção de uma indignidade do trabalhador na proporção inversa à valorização do produto, pois que

quanto mais civilizado seu objeto, mais bárbaro o trabalhador; quanto mais rico de espírito o trabalho, mais pobre de espírito e servo da natureza se torna o trabalhador. (...)

O trabalho produz maravilhas para os ricos, mas produz privação para o trabalhador. Produz palácios, mas cavernas para o trabalhador. Produz espírito, mas produz imbecilidade, cretinismo para o trabalhador. (Op. Cit. p. 82)

Dizer que o processo de produção produz cavernas para o trabalhador é dizer que há um processo contrário a um processo de iluminação, de consciência do mundo, de apropriação da realidade. O trabalhador torna-se objeto de si e do mundo, servindo para o senhor capital que lhe subtrai energia e mais-valia, na mesma medida em que rouba sua percepção crítica da realidade.

É assim que Marx arremata nos dizeres:

Chega-se, por conseguinte, ao resultado de que o homem(o trabalhador) só se sente como [ser] livre e ativo em suas funções animais, comer, beber e procriar, quando muito ainda habitação, adornos, etc., e em suas funções humanas só [se sente] como animal. O animal se torna-se humano, e o humano, animal.

No âmbito da ideologia criminal punitiva, o processo de encarceramento é uma ferramenta de poder da classe dominante que age física (com o controle da liberdade do desviante) e subjetivamente (com a dominação ideológica de subserviência).

A alienação se baseia primeiro com uma doutrinação de quem é o criminoso, no momento em que coloca-se a etiqueta de bandido com base em uma inaceitabilidade da sociedade burguesa àquele membro de classe desfavorecida. Assim, a política legal de exclusão confirma e fortalece a luta de classes, pois que legitima os signos excludentes da sociedade nela mesma.

Em momento posterior ao do etiquetamento, o desviante pode começar a se enxergar enquanto criminoso e corresponder às expectativas de ação das instituições jurídicas que o condenou, momento este que se percebe as primeiras consequências da alienação do homem pelo cárcere. Esse, que de sujeito explorado virou coisa, coisa não querida e indesejada e que merece ser isolado do convívio social, passa a se sentir coisa, produto de uma engrenagem, objeto da produção capitalista do crime e do criminoso (o humano virou animal). 
Esse é um contexto que diz respeito às funções declaradas e as penas não-declaradas da prisão, da ideologia penal dominante que tem uma eficácia invertida e da "gestão politica da miséria" ${ }^{3}$ de orientação neoliberal.

Sobre a função histórica da prisão e como está imbricada aos objetivos do capitalismo, Vera Regina Andrade (2014, p. 306) declara:

\begin{abstract}
A prisão é a pena por excelência do capitalismo, assim como, por exemplo, o açoite foi a pena do escravismo. Todo método punitivo tem por função reproduzir a estrutura social que lhe corresponde e, portanto, a função da prisão é conservar e reproduzir a ordem social capitalista, ao lado de outros mecanismos de controle que lhe dão sustentação, como o mercado de trabalho e a escola. Isso significa afirmar que a prisão, como todos os outros métodos punitivos, é um método ontológico; ela vai durar como tal, enquanto durar a sua funcionalidade na estrutura social capitalista, porque ela é o espelho das estruturas e da ordem, e as reproduz, tanto que a melhor forma de conhecer essa ordem é conhecer a própria prisão.
\end{abstract}

Como consequência, a prisão está a serviço do controle e da reprodução da desigualdade social, é mais uma forma de gestão de classe, é lugar de controle em que uma classe diz, ainda que simbolicamente através de um discurso legal, que tem o domínio sobre o corpo e a mente da outra.

Continua Vera ao denunciar a lógica da seletividade à qual a prisão atende: “A função da prisão, nesse segundo eixo deslegitimador, não é o combate à criminalidade, por meio da ressocialização, do castigo e da intimidação, é a construção de criminosos, é a fabricação de criminosos" (Op. Cit. p.306)

\title{
2.2. O materialismo e a criminologia
}

O olhar marxista do Direito foi modificado pela influência da sua maturidade intelectual, do jovem que acreditava em um Direito de justiça social ao filósofo maduro que entendeu serem incompatíveis a coexistência do sonhado comunismo e do Direito, pois esse seria uma instituição a serviço do capitalismo.

Na obra "Karl, meu amigo", Roberto Lyra Filho traz essa perspectiva dialética das posições de Marx no decorrer de sua vida. Em um primeiro momento, em sua juventude, Marx teria afirmado o Direito, assim constituído em uma tese: "Direito... é a existência positiva de liberdade...

\footnotetext{
${ }^{3}$ Expressão cunhada por Massimo Pavarini na obra “Control y dominación. Teorias criminológicas burguesas y proyecto hegemonico".
} 
Liberdade é o direito de fazer e buscar tudo o que a outrem não prejudica" (MARX, apud LYRA FILHO, 1983, p.68).

Já em “A ideologia Alemã”, chegou à negação total do Direito, formulando uma antítese: "Quanto ao direito, acentuamos, em oposição a muitos, a antinomia do comunismo e do direito, tanto público e privado, quanto sob a forma, de máxima generalidade, dos direitos dos homens". (MARX, apud LYRA FILHO, 1983, p.68).

Por fim, havendo uma negação da negação, chegou a uma síntese:

O comunismo não retira a ninguém o poder de apropriar-se de sua parte dos produtos sociais, apenas suprime o poder de escravizar o trabalho de outrem, por meio dessa apropriação... A luta pela emancipação das classes trabalhadoras não significa uma luta por privilégios e monopólios de classe, e sim uma luta por direitos e deveres iguais, bem como pela emancipação de todo domínio classístico” (MARX, apud LYRA FILHO, 1983, p.51)

Marx, portanto, afirma certos princípios do Direito quando estes têm ligação com a realidade, quando ilustram ideais profundos de justiça social, mas não acredita ser este o meio para a emancipação humana, nem o Direito, nem a política. Nessa esteira, Marilena Chauí diz que "O papel do Direito ou das leis é o de fazer com que a dominação não seja tida como uma violência, mas como legal, e por ser legal e não violenta deve ser aceita. A lei é direito para dominante e dever para o dominado". (CHAUÍ, 1980, p. 90).

Nesse sentido, Marx considerava que a emancipação humana, que não se confunde com a emancipação social, é mais que o Direito, já que o Direito é forma de garantir a ordem social, é instrumento de manutenção do poder e, por isso, classista. Por isso, a emancipação humana (real, prática e desalienada) é maior que a emancipação política, porque esta mantém o status quo.

Assim sendo, o primeiro passo da emancipação humana é pôr fim à alienação decorrente do capitalismo e o segundo passo é conseguir igualdade real entre os homens (aqui ele critica a igualdade irreal, igualdade ilusória proclamada pela burguesia e que esconde as desigualdades). Quem vai promover essa emancipação? O proletariado. Como? Através da revolução comunista como transição para o socialismo.

Sobre a função do Direito penal para a burguesia, Henri Lefebvre(1968, pp. 79 e 80) faz uma análise do que significa na visão marxista:

Um filósofo produz idéias, um poeta versos, um pastor sermões, um professor manuais etc. Um criminoso produz crimes. Se considerarmos um pouco mais de perto a relação que existe entre este ramo da produção e o conjunto da sociedade, revelaremos muitos preconceitos. O criminoso não produz apenas crimes, mas ainda o Direito Penal, o professor que dá cursos sobre Direito Penal e até o inevitável manual onde esse professor condensa o seu ensinamento sobre a verdade. Há, pois, aumento da riqueza nacional, sem levarmos em 
conta o prazer do autor. O criminoso produz ainda a organização da polícia e da Justiça penal, os agentes, juizes, carrascos, jurados, diversas profissões que constituem outras categorias da divisão social do trabalho, desenvolvendo as faculdades de espírito, criando novas necessidades e novas maneiras de satisfazê-las. Somente a tortura possibilitou as mais engenhosas invenções mecânicas e ocupa uma multidão de honestos trabalhadores na produção desses instrumentos. O criminoso produz uma impressão, que pode ser moral ou trágica; desta forma ele auxilia o movimento dos sentimentos morais e estéticos do público. Além dos manuais de Direito Penal, do Código Penal e dos legisladores, ele produz arte, literatura, romances e mesmo tragédias. $O$ criminoso traz uma diversão à monotonia da vida burguesa; defende-a do marasmo e faz nascer essa tensão inquieta, essa mobilidade do espírito sem a qual o estímulo da concorrência acabaria por embotar. O criminoso dá, pois, novo impulso às forças produtivas... (grifo meu)

A abordagem sobre o crime e a criminalidade na obra marxista tem um eixo central: o crime é analisado como o produto da sociedade de classes. Exemplo disso é o texto "A condição da classe trabalhadora na Inglaterra", em que Engels argumenta que a degradação dos trabalhadores ingleses, acarretada pela expansão da produção fabril, despojava-os de vontade própria, conduzindoos inevitavelmente para o crime. A pobreza fornecia a motivação, e a deterioração da vida familiar interferia na educação moral adequada das crianças. Engels observou, porém, que o crime é uma reação individual à opressão, ineficaz e facilmente esmagada. Por esse motivo, os trabalhadores cedo voltaram-se para formas coletivas de luta de classes. Mas o ódio de classe, alimentado por essas reações coletivas, continuava a dar lugar a algumas formas individualistas de crime.

É por assim dizer, que quando se firma a divisão da sociedade em proprietários e nãoproprietários é possível visualizar a exclusão no processo de produção que se desenrola na exclusão social e criminalização tanto primária (no âmbito de produção da norma), quanto secundária (no âmbito de interpretação e aplicação da norma).

Portanto, como bem sintetiza Vera Andrade, a prisão ao reproduzir a desigualdade social, é lugar de gestão de classe, que é complementar ao mercado de trabalho e obedece à lógica da seletividade, além de, como depreendemos dos postulados de Marx, ser lugar de alienação da classe trabalhadora

\section{CONSIDERAÇÕES FINAIS}

Do percurso dialético que se percorreu conjugando a criminologia e parte simbólica do pensamento marxista, foi possível fazer, como nos aconselhou o revolucionário socialista, se valer da arma da crítica, mas sem abrir mão da crítica das armas. 
Essas armas não são apenas as que o Estado penal policialesco se utiliza em nome da (in) segurança pública/ jurídica, mas as armas ideológicas de manutenção de poder e subjugo de classe. É a arma da alienação pelo direito, é a arma de alienação pelo capital, é a arma de alienação do burguês sobre o proletário.

As mãos que empunham tais armas são as responsáveis por administrar uma política (capitalista neoliberal) de criminalização da pobreza em nome de um direito que aplica a seletividade para decidir o que é crime e quem é o criminoso, com fito de atender aos interesses da classe dominante.

A escravidão contemporânea é também ideológica e acontece na condição em que o trabalho, ao invés de ser instrumento para a realização plena do homem, torna-se, pelo contrário, um instrumento de desumanização, tendo sua vida e seu valor medidos pela capacidade de produzir e acumular.

O homem alienado é transformado em bagaço (sem desfrutar do suco do capital), se perde de si na engrenagem espoliativa. É a história do homem que virou suco $^{4}$, e também do homem que constata esse continuo esmagar de pessoas, essa estrutura que faz desaparecer o que há de mais humano nos homens: sua capacidade de pensar, construir-se e compartilhar suas expressões, coisificando-os e homogeneizando seus pensamentos.

A revolução é, portanto, a historia do homem que não quer virar suco, que se opõe à pasteurização de sua vida, que luta contra a constante opressão sofrida, desde o depósito em porões da miséria, até a violência do Direito que não nota sua presença, não distingue sua diferença e o marginaliza, condenando-o a um crime que nunca cometera. Este sujeito da história, que se apropria de sua consciência de classe, não seria mais um Severino de vida severina que não faria falta em meio à sociedade massificadora.

\section{REFERÊNCIAS BIBLIOGRÁFICAS}

ANDRADE, Vera Regina Pereira de. A ilusão de segurança jurídica: do controle da violência à violência do controle penal. 2. Ed. Porto Alegre: Livraria do Advogado Editora, 2003.

\section{ANDRADE, Vera Regina P. de. Pelas mãos da Criminologia: O controle penal para além da (des)ilusão. Rio de Janeiro: Revan, 2014.}

\footnotetext{
${ }^{4}$ Referência ao filme "O homem que virou suco", de 1981, dirigido por João Batista de Andrade, que conta a estória de um poeta nordestino confundido com um assassino e criminalizado. É uma sátira do capitalismo e sua mão nada invisível para punir os pobres.
} 
CHAUÍ, Marilena. O que é ideologia? São Paulo: Brasiliense, 1980.

CHRISTIE, Nils. Uma razoável quantidade de crime. Rio de Janeiro: Revan. 2013

CIRINO DOS SANTOS, Juarez. A Criminologia Radical. 3. Ed. Curitiba: ICPC: Lumen Juris, 2008.

CIRINO DOS SANTOS, Juarez. Memorial criminológico - ou a necessidade de retomar Marx. In: http://icpc.org.br/wp-content/uploads/2015/06/Memorial-Criminologico.pdf Acesso em: 25/08/2016.

FOUCAULT, Michel. Vigiar e punir: nascimento da prisão. Petrópolis: Vozes, 1987

LEFEBVRE, Henri. Sociologia de Marx. Rio de Janeiro: Forense, 1968.

LYRA FILHO, Roberto. Karl, meu amigo: diálogo com Marx sobre o Direito. Porto Alegre: Sérgio Fabris Editor, 1983.

MARX, Karl. História. (Organizador Florestan Fernandes). (Col. Grandes cientistas sociais). São Paulo: Ática, 1985.

MARX, Karl. A questão judaica. São Paulo: Ed. Boitempo, 2010.

MARX, Karl. Manuscritos Econômicos Filosóficos. (Tradução e Notas Jesus Ranieri). São Paulo: Boitempo Editorial, 2015.

MARX, Karl. O Capital: Crítica da economia política. Livro I: O processo de produção do capital. São Paulo: Boitempo editorial, 2013.

MARX, Karl; ENGELS, Friedrich. A ideologia alemã. (introdução de Jacob Gorender e tradução Luis Cláudio de Castro e Costa). São Paulo: Martins Fontes, 1998.

MELOSSI, Dario e PAVARINI, Massimo. Cárcere e fábrica - As origens do sistema penitenciário (séculos XVI e XIX). Rio de Janeiro: Revan/ ICC, 2006

MELOSSI, Dario. A questão penal em O capital. In: Revista Margem Esquerda - Ensaios marxistas, n. 4. São Paulo: Boitempo, 2004

MENEGAT, Marildo. O olho da barbárie. São Paulo: Expressão Popular, 2006

PASUKANIS, Eugeny Bronislanovich. A teoria geral do Direito e o marxismo. Rio de Janeiro: Renovar, 1989

PAVARINI, Massimo. Control y dominación. Teorias criminológicas burguesas y proyecto hegemonico. Mexico: Siglo XXI, 1988)

RUSCHE, Georg; KIRCHHEIME, Otto. Punição e estrutura social. Rio de Janeiro: Revan, 2004. 